\title{
A Case Study on L2 Learning Strategies of Middle-Aged Learners
}

\author{
Lyu Liangqiu ${ }^{1} \&$ Xu Zhengqiu ${ }^{1}$ \\ ${ }^{1}$ School of Foreign Languages, North China Electric Power University, Beijing, China \\ Correspondence: Xu Zhengqiu, School of Foreign Languages, North China Electric Power University, Beijing, \\ China.
}

Received: December 16, 2018 Accepted: February 15, 2019 Online Published: February 18, 2019

doi: $10.5539 /$ elt.v12n3p214

URL: https://doi.org/10.5539/elt.v12n3p214

\begin{abstract}
There are many researches about learning strategies of adolescent students and adult learners, but few on learning strategies of middle-aged learners. Through a case study, the paper finds out that middle-aged learners use six classes of learning strategies in a high frequency, especially cognitive strategies, meta-cognitive strategies and social strategies. But compensation strategies, memory strategies and affective strategies were used at a lower frequency. The factors of age and life experience as well as cultural background are of great significance for the choice of using certain learning strategies. The results of the study also show that SILL is of high reliability for the study on learning strategies of Chinese second language learners.
\end{abstract}

Keywords: L2 Learning strategies, middle-aged learners, SILL

\section{Introduction}

In recent years, English learning and teaching have been largely changed with advances in information technology and there is the rise of blended learning which is bound to change the contents, means and concepts of English education, as well as gives students more choices about the contents and methods of learning (Hao). But one of the skills that must be acquired for success in learning is to know how to learn, that is, to master effective learning strategies (Wang). However, the studying scope of learning strategies are limited to adolescent students, while little study on adult learners, not to mention middle-aged learners. The current situation of middle-aged learners in second language acquisition in China is not fully studied. Whether Middle-aged students have sufficient awareness and attention to second language learning strategies, and there is any difficult to habitually apply a series of effective and reasonable strategies to second language learning? This paper tries to answer these questions.

Domestic and foreign researchers have made extensive research in this field, and have achieved a large number of research results, among which foreign countries have made some meaningful explorations in this field with Oxford's SILL as a widely accepted tool (Li \& Zhang, 2018). However, most of the studies are conducted in the context of western language learning. So it is necessary to study the use of learning strategies by middle-aged second language learners in Chinese surroundings.

A man in his middle age, named Mr. K. for short, takes a full-time academic graduate study of English. It is over 20 years that he has attended a junior college and a school of continuing education. Then after five times of failing in the graduate entrance exam, he succeeded to enter into a graduate school. It is no doubt that Mr. K. has his own living and life style. It is worthy of carefully studying the learning strategies that he used in the past 20 years of learning English. This study, based on the current situation of College English Teaching in China, takes Mr. K. as the research object, and probes into the frequency and causes of utilizing English learning strategies by means of Oxford's Strategy Inventory for Language Learning (Version for speakers of other Language Learning English). Finally, the paper analyzes and discusses the factors that cause this situation, and recommends some effective ways to solve this problem.

\section{Literature Review}

Language learning strategy is a popular issue in language learning research. The study of learning strategies in second language and foreign language begins in the mid-1970s. Since then, foreign language researchers have aired their unique opinions on the definition of learning strategies to reveal the nature and characteristics of learning strategies from different perspectives. Meanwhile, domestic scholars' research on English learning strategies has gradually shifted from the macro field to the micro field, characterized by the gradual enlargement 
of the scope and the development of the depth, and the enhance of the level of study (Liu, 2009). However, the distribution of research scope is not balanced (Xu, 2008). English researchers pay more attention to reading, vocabulary and listening learning strategies, but there is a lack of research on learning strategies such as writing and speaking (Sun, 2007). Moreover, the types of research methods are relatively simple. Most of the experimental data came from questionnaires, and experimental studies, with case studies and mixed research methods rarely used. The following is the views that have been representative and influential ones in the field of language learning strategies in recent years, and are widely accepted by people. Learning strategies are approaches or the techniques used by a language learner to describe the specific form of visual behaviors in Stem's opinion (1983). Cohen (1998) also refers to language learning strategies as the learners' conscious or semi-conscious behavior and psychological activities. The paper prefers Oxford's view that language learning strategies are behaviors or actions taken by learners for language learning to be more successful, freer and more enjoyable (1990). Oxford also summarizes the following factors that exert a significant influence on choosing learning strategies in second language acquisition, namely, motivation, attitudes and concept, modes of learning as well as gender.

It is generally believed that effective learning strategies can help learners to improve the efficiency of acquiring foreign languages. However, it is indispensable to have a comprehensive and clear understanding of the learners' use of strategies before instructing learners to use the new learning strategies, so that they can be guided scientifically and effectively. A quick and effective way to understand learning strategies is to scientifically measure students' learning strategies. The abstraction and complexity of learning strategies brings higher requirements for the compilation and selection of corresponding measurement tools.

There is no consensus on the classification of language learning strategies between language researchers with diverse starting points and emphases. For instance, O'Malley and Chamot (1987) divide learning strategies into junior learner' strategies, intermediate learners' strategies, and senior learners' strategies according to the learners' level, while according to Oxford's (1990) views, there are two kinds of learning strategies, namely, direct learning strategies and indirect learning strategies, concerning whether strategy directly affects the learning process. Direct strategies can be divided into memory strategies, cognitive strategies and compensation strategies. Indirect strategies can also be divided into meta-cognitive strategies, affective strategies and social strategies. The main object of the study of English learning strategies is college students and postgraduate students. The scope of the research is mainly focused on English reading, listening, writing and vocabulary (Liu, 2004). She designed Strategy Inventory for Language Learning (SILL) which has been revised several times to become a popular standard measure of language learning strategies and called a valuable diagnostic tool by applied linguist Ellis (1994). The scale adopts the form of a questionnaire of fifty items, measuring six kinds of language learning strategies respectively. The participants, according to their actual situation, evaluate each statement to their own extent on each item on the Likert Scale, the 5-point scale. In the views of Oxford (1990: 199), SILL is confirmed to be an effective and reliable measuring tool through field experiments. And the quantity of the tool is well received by researchers in many linguistic studies around the world.

Oxford (1989) said that through the training of learning strategies, students can use learning strategies more consciously, and students can be better at using appropriate strategies. Many researchers believe that learning strategies can be taught, and strategy training is feasible and effective. A large number of studies on learning strategy training have expounded the feasibility of language learning strategy training. Learning strategy training can make language learners master the strategies of good learners, improve language skills and achievements, and then enhance learning motivation and autonomy. So strategy training should be part of a foreign language teaching course.

\section{Case Study on L2 Learning Strategies of Middle-Aged Learners}

Since put forward, case studies are questioned about its scientific significance (Zhang). Many scholars testified the quality of case studies from several perspectives, such as Fei Xiaotong's approach of classification comparison, Clifford Geertz's thick description, Michael Burawoy's extended case method as well as Wang Fuwei's relational case study and others. The theoretical orientation of case studies can be diversified: either a generalization of the society to which they belong, or a new conceptual insight, or a reconstruction of existing theories or the construction of situational theories (Wang). Therefore, the paper aims to draw a general conclusion about the feature of learning strategies of middle-aged learners by means of a case study.

\subsection{The Participant of the Study}

The participant of the study was a full-time English postgraduate, Mr. K., School of Foreign Languages, North China Electric Power University, Beijing, China, who is in his forties and has a high level of English proficiency 
with TEM-8 certificate. It is rare that a man in such age learns English in graduate schools, and his learning experience is also unusual. It is over 20 years that he has attended a junior college and a school of continuing education. Then after five times of failing in the graduate entrance exam, he succeeded in entering into a graduate school. It is no doubt that Mr. K. has his own living and life style. It is worthy of carefully studying the learning strategies that he used in the past 20 years of learning English. This study, based on the current situation of College English Teaching in China, takes Mr. K. as the research object, and probes into the frequency and causes of utilizing English learning strategies of middle-aged learners by means of Oxford's Strategy Inventory for Language Learning (Version for speakers of other Language Learning English). Finally, the paper analyzes and discusses the factors that cause this situation, and recommends some effective ways for middle-aged learners.

\subsection{Research Methods}

Logically dealing the study, the study utilizes an experimental research design with interviews and a survey to measure the learning strategies of an English postgraduate to figure out the frequency and reasons of using learning strategies. Three questions are involved in the interview:

(1) Can you talk about your English learning experience?

(2) Do you have any English Learning skills?

(3) How did you get through the five fails in the graduate entrance exam?

As for choosing the measuring tool for this study, it is not enough to arrange an interview to know the learning strategies and learning experience of the participant. The main reason is that the participant may be not accustomed to express his real ideas openly in a face-to-face interview, which will affect the quality and validity of the data collected to some extent. Therefore, Strategy Inventory for Language Learning (SILL) (Version for speakers of other Language Learning English) is used as a measuring tool for this research (Oxford, 1990: 293). And SILL is the most comprehensive and influential classification model, language learning curator, created by Rebecca L. Oxford. The figures in the Likert scale are analyzed through SPSS 12.0. In addition, conclusions drew from the survey can be related to the personal situation of the participant.

\subsection{Research Procedures}

An appointment was made with the participant for a short interview about the basic situation of age, class, gender, learning style (professional / amateur) and most importantly his English learning experience. Then the participant was asked to fill out the questionnaire of SILL after the interview. Before starting to fill in, the research was introduced in a brief and concise way, and then the participant was arranged to complete the work in 30 minutes. In order to prevent the participant from providing the expected answers, the participant was informed that respondents in the SILL scale were no right or wrong and his answer must be genuine. If the participant had difficulties in understanding a certain problem, he can ask for help. Finally the questionnaire was retracted after the prescribed time. It is worth reminding that a letter was given to the participant asking for approval of the conduct of the study and all the data collected has obtained his permission.

\subsection{Data Analysis and Discussion}

When all the above procedures are over, all the data collected are analyzed as follows in order to figure out the frequency and causes of utilizing English learning strategies.

\subsubsection{Analysis of the Data From the Interview}

When asked about his English learning experience, he mentioned that it was over twenty years ago that he had access to English and had continued to learn English for about six years during junior and senior year of high school when he can deal with the basic vocabulary and grammar of English satisfactorily. Later, he started learning English again by self-learning after work ten years ago. He recited the words in the English-language textbooks for middle and high school and New Concept English as many as he can by reading and copying the words and sentences every day, meanwhile he practiced his listening by means of listening to the self-contained audios when he was exercising, preparing meals or just walking around. Then, his English self-study went on by visiting many English teaching classes and studying the third volume of College English Textbook on his own when he was in a junior college. The learning experience was a challenge for him, but all his persistence and diligent paid off as he passed College English Test, Band 4 and the upgrading examination. And he grasped the opportunity to attend the three-year English course for Bachelor's degree at School of Continuing Education of Beijing Foreign Studies University, where his English proficiency was improved largely. So he made up his mind to take part in the postgraduate entrance exams for a postgraduate study in English. He failed five times, and finally he succeeded to be an English postgraduate at School of Foreign Languages, North China Electric Power University last year. It is 
clear from his words that he has had an English learning experience of more than 20 years with persistence that is difficult to reach by ordinary people. He was largely self-taught and self-encouraged in English and reached a high level of competence from his learning experience above.

As for his learning skills, mastering the knowledge of English language is just like weaving a net. Only by sticking each knot on the net can this dense net be a powerful tool. In addition, his insistence to English owes to his keen interest in English, and a firm faith that a long-term accumulation will eventually achieve a certain degree of success. In short, studying English is a mode of life for him. Finally, he said that attention should be put on how to master knowledge, but not negative emotions. Of cause, he is also troubled by negative emotions, such as anxiety, irritability, and inferiority and others in English learning, especially when he faced five fails continuously in the graduate entrance exam. Encouraging himself to insist on is the most effective way to overcome these negative emotions. And some success he obtained in learning has inspired him that no pain no gain, only hard to be successful.

In short, in Mr. K.'s words, it is clear that middle-aged learners are skillful in self-motivation and self-management which are the typical manifestations of cognitive strategies. In addition, middle-aged learners seldom show their emotions and tend to ignore the negative emotions rather than resettle them, which indicates that affective strategies are not their favorite ones. Last but not least, middle-aged learners have the difficulty in taking fully advantage of information technology. Various advanced functions and a large number of shared resources in the Internet not only provide a wider space for students to learn English, but also improve the learning efficiency and quality (Shu).

\subsubsection{Analysis of SILL}

The collected data from SILL are analyzed statistically. The overall mean, standard deviation and median are illustrated in the following table.

Table 1 . The frequency of learning strategies usage

\begin{tabular}{llll}
\hline Parts of SILL & Overall Mean & Standard Deviation & Median \\
\hline Part A & 3 & 1.155 & 3 \\
Part B & 4.124 & 0.773 & 4 \\
Part C & 2 & 1 & 2 \\
Part D & 4.556 & 0.831 & 5 \\
Part E & 2.667 & 0.745 & 2.5 \\
Part F & 4.333 & 0.735 & 4.5 \\
Total & 3.62 & 1.263 & 4 \\
\hline
\end{tabular}

In the table, Part $\mathrm{A}(\mathrm{Q} 1-9)$ shows the memory strategies, Part $\mathrm{B}(\mathrm{Q} 10-23)$ cognitive strategies, Part $\mathrm{C}(\mathrm{Q} 24-29)$ compensation strategies, Part $\mathrm{D}(\mathrm{Q} 30-38)$ meta-cognitive strategies, Part E(Q39-44) affective strategies and Part $\mathrm{F}(\mathrm{Q} 45-50)$ social strategies.

The high and low frequency of learning strategies is determined by the averages proposed by Oxford (1990). The averages of high usage frequency are 3.5-5.0, medium frequency of use is 2.5-3.4, and low frequency of use is 1.0-2.4. According to the table of the Frequency of Learning Strategies Usage, in general, the participant uses the six major categories of learning strategies in a high frequency, which has something to do with his high level of English. In spite of this, he also has preferences or dislikes. For instance, compared with other kinds of learning strategies, cognitive strategies, meta-cognitive strategies and social strategies are used frequently with an operating frequency of more than 4 , while memory strategies, compensation strategies and affection strategies are used less. The reasons behind this phenomenon will be illustrated in detail later.

Firstly, high frequency in cognitive strategies, meta-cognitive strategies and social strategies is closely related to the age of the participant. The participant learns English almost in his adult life by self-learning. He, in his middle age, not only powerful cognitive ability, but also abundant cognitive experience. Learning activity includes a complex cognitive process where the learner's cognitive experience is the prerequisite (Hu \& Zhang, 2006). And a variety of life experience helps middle-aged learners to understand that actions which make sense in one framework may be unintended consequences elsewhere. In addition, middle-aged learners may develop the 
second language as a separate language as a separate system and eventually thinks in the way of second language. At the same time, the influence of the first language on the learning of the second language might be positive and helpful. So middle-aged learners are good at using cognitive and meta-cognitive strategies for self-learning English. Middle-aged learners can organize his learning process, learning content as well as learning time independently and evaluates the learning efficiency, so as to find a learning style that suits them to achieve high learning effectiveness. In addition, with rich social experience, middle-aged learners are aware that language is not only a complex system of grammar or vocabulary, but also a useful and indispensable tool for communication. They pay special attention to communicate with others in English to improve oral skill.

Secondly, this table also shows that the participant is less likely to use the learning strategy of emotional interaction. Adult learners' personality and their cultural background may be the key factors to produce this phenomenon. The cultural background of our country determines that the learners attach importance to face saving and tend to be quiet and introverted. Therefore, it is difficult for middle-aged learners to realize the importance of reducing learning anxiety, motivate themselves and cooperation with others in the learning process. Adult learners in China are not good at motivating themselves and grasping their emotions in learning. According to Oxford (1990), these are important components of emotional strategies.

Thirdly, this study also found that the participant has less use of memory strategies. And memory strategies are not very recognized by him as an adult learner in second language learning. Memorizing words and phrases may be a very boring thing for him. Moreover, it is known that human memory is at the peak of memory at the age of $16^{\sim} 23$, and the rate of memory error is the lowest. It is normal to realize that memory decreases with age. With the increasing of age, the permanent memory will have a greater chance to improve, but the short-term memory will be less than the previous one. As middle-aged learners have a relatively short memory span, memory strategies are out of their best choice.

Finally, compensation strategies are the last ones the participant uses, which is consistent with the study of Li Jiongying (2002) and Liu Yaling (2004). Their research shows that Chinese students seldom use compensation strategies or use them frequently. The active use of compensation strategy means that students can make up for the lack of knowledge in understanding and using the target language by means of context and prediction of the purpose of others consciously, so as to overcome the language barriers encountered. As more attention is paid to English learning and English test, the common compensation methods of meaning guessing from context and euphemism expressions are helpful in daily learning and test taking.

In brief, middle-aged learners have the ability to actively regulate their language learning processes and communicate with others with the increasing frequency of the use of cognitive strategies, meta-cognitive strategies and also social strategies. However, middle-aged learners may be not very good at managing their emotions and cannot effectively overcome negative emotions and emotional barriers in second language learning, such as anxiety, lack of confidence, fear of failure, etc. Besides, middle-aged learners are subject to be troubled by poor short-term memory. Finally, it is not easy for middle-aged learners to take modern educational technology as part of their learning

\section{Conclusion}

The study shows that middle-aged learners can have a high frequency of using learning strategies in general, which can bring about a high level of English proficiency. But some specific learning strategies are used as a low frequency which may impede the efficiency of second language learning. As for middle-aged learners, it is recommended to gain deep insight into effective strategies and realize the significance of managing emotions. And the teacher's instruction may be very helpful. In addition, much attention should be paid to compensation strategies which may contribute to successful conversation and also good grades in examinations. Applying images and placing words into context may be efficient methods of enlarging memory capacity. Last but not the least, middle-aged learners are supposed to make the best of modern educational technologies, such as multimedia technology and shared online resources and others.

\section{Acknowledgement}

Supported by Teaching and Learning Reform Project in North China Electric Power University: Curriculum System Construction of Translation Major. Project Number: XM1805212.

\section{References}

Chamot, A. (1987). The learning strategies of ESL students. In Wenden \& Rubin (Eds.), Learner Strategies in Language Learning. Englewood Cliffs, N. J.: Prentice Hall.

Cohen, A. D. (1998). Strategies in Learning and Using a Second Language. London: Longman. 
Ellis, R. (1994). The Study of Second Language Acquisition. Oxford: Oxford University Press.

Hu, Y., \& Zhang, W. M. (2006). College Students' Ability of Using meta-cognitive Strategies. Foreign Language Education, 3.

Hao, Z. J., Zhang, F. C. Xu, J., \& Hou, X. X. (2018). The Present Situation and Promotion Strategy of College Students' Deep Learning in the Network Learning Space-Based on a Survey of Students Majoring in Educational Technology in H University. Digital Education.

Li, J. L. (2002). A Case Study on L2 Learning Strategies of Chinese and its Application. Foreign Language Education, 1 .

Li, W., \& Zhang, J. (2018). A Meta-analysis of the Correlations in SILL-based Studies on Chinese University Students' Language Learning Strategies and English Learning Achievement in China. Foreign Language Learning Theory and Practice, 4.

Liu, Y. (2009). A Research Overview on L2 Learning strategies. Journal of Language and Literature, 1.

Liu, Y. L. (2004). A Differential Study on English Learning Strategies of College students. Theory and Practice of Education, 3.

Oxford, R. (1989). Use of Language Learning Strategies: A Synthesis of Studies with Implications for Teacher Training. System, 17, 235-47. https://doi.org/10.1016/0346-251X(89)90036-5

Oxford, R. (1990). Language Learning Strategies: What Every Teacher Should Know. Rowley, Mass: Newbury House.

Stern, H. H. (1983). Fundamental Concepts of Language Teaching. Oxford: Oxford University Press.

Sun, N. (2007). A Case Study on L2 Learning strategies of Adult Learners. Journal of Xi'an international Studies university, 3 .

Shu, Q. F. (2018). Research on the Application of Modern Educational Technology in English Learning Strategies at Middle School. Education Modernization, 26.

Wang, Z. (2018). Construction of College English Learning Strategy System in Applied Colleges Based on Blended Learning. Journal of Higher Education, 22.

Wang, F. W. (2012). The Significance and Limitation of Case Study: Based on the perspective of knowledge growth. Sociological Studies.

Xu, S. (2008). The Reliability of strategy Inventory for Language learning. Journal of Guizhou Educational Institute (Social science), 4.

Zhang, Y. Y., \& Zhang, H. D. (2018). Research on the Representativeness of Case Studies. Journal of University of Jinan (Social Science Edition), 1.

\section{Copyrights}

Copyright for this article is retained by the author(s), with first publication rights granted to the journal.

This is an open-access article distributed under the terms and conditions of the Creative Commons Attribution license (http://creativecommons.org/licenses/by/4.0/). 